\title{
EDUCATION, TRAINING AND WORK UNDER \\ NEOLIBERALISM IN SOUTH AFRICA: TOWARD ALTERNATIVES
}

\author{
Salim Vally \\ University of Johannesburg, South Africa \\ svally@uj.ac.za
}

Enver Motala

Nelson Mandela Institute

University of Fort Hare, South Africa

emotala1@gmail.com

\section{ABSTRACT}

This article conceptualises the overall relationship between a democratic society, socially useful labour and its implications for education and training and unemployment, particularly youth unemployment. The article analyses the ideas and practices that are dominant in the language, ideologies and practices of human capital theory-a theory which has mutated and survived through its various incarnations. We begin by examining the culture of "job consciousness" critically. Thereafter, we explore the implications of unemployment for conceptions of work and education and follow this examination by discussing alternative and socially useful forms of the organisation of work. Finally we deal with the meaning of these alternatives for educational processes and learning and conclude with concrete instances and possibilities based on the production of socially necessary and useful goods and services-outside the forms of commodification that are at the heart of capitalist production.

Keywords: alternative education; commodification; education and neoliberalism; education and work; socially useful labour; unemployment

Now we have seen that the semi-theological dogma that all labour, under any circumstances, is a blessing to the labourer, is hypocritical and false; that, on the other hand, labour is good when due hope of rest and pleasure accompanies it. We have weighed the work of civilization in the balance and found it wanting, since hope is mostly lacking to it, and therefore we see that civilization has bred a dire curse for men. But we have seen also that the work of the world might

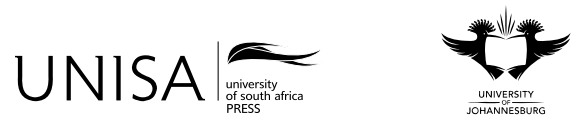


be carried in hope and with pleasure if it were not wasted by folly and tyranny, by the perpetual strife of opposing classes. (Morris [1888] 2008, 27-8)

\section{INTRODUCTION}

How does one conceptualise the overall relationship between a democratic society, socially useful labour (especially forms of work and livelihoods outside the formal labour market), and education and training? What specifically are the implications of such a relationship for education and training? This article is dedicated to the praxis of Patrick van Rensburg who grappled with these questions. Van Rensburg died in May 2017. The last section of this article explores Van Rensburg's concrete projects and his lifelong passion for "education with production." The latter constituted an alternative model of education and the potential for building a more just society is provided. This article also contests the ideas and practices that are dominant in the language, ideologies and practices of human capital theory - a theory which has mutated and survived through its various incarnations. A wide range of critical approaches to the dominance of human capital theory and its implications has re-emerged in many places and needs to be reckoned with (Brown et al. 2011; Hyslop-Margison and Sears 2006; Klees 2017; Vally and Motala 2014).

Human capital theory and its adherents are intent on grinding on regardless of the critique. In some ways this is not surprising because a bald summary of the research about Post School Education and Training (PSET) in South Africa takes for granted that its reach is confined to the formal education and training system, its remit being largely about the relationship between such a system and the formal labour market and economy. These approaches lie squarely within the fold of "human capital" theory and its application. The book Education, Economy and Society (Vally and Motala 2014) provides our refutation of the underlying foundations on which human capital theory rests.

In the latter sections of this article, we pay particular attention to outlining some of the alternative approaches to work and education. Far from inventing these alternatives, we build on an accumulated body of practical experience and conceptual thinking about what is entailed in the conception of a wide range of demonstrable alternatives to the conventional and dominant approaches defining the relationship between learning and work. In effect, the approach we take is unconstrained by the idea that there can be no alternative to the prevailing forms of work based on the requirements of capitalist labour markets. Perspectives that are sceptical about these possibilities reside in the discourse of "there can be no alternative." We hope to show that the possibilities for reconstituting the relationship between education and training even within the present capitalist mode of production are hardly novel and have been deliberately muted by the authority of market-based systems and their ideologies. We do not regard the power and reach of these systems as unassailable, permanent or as a "natural" state of affairs not 
susceptible to human agency. We understand that dystopia ridden social systems are considerably resistant to change and that a great deal of social agency is required for that to happen. The endurance of global corporate capital, despite its continuing cycles of "boom and bust," wreaks havoc on the lives of millions of human beings in societies everywhere. Yet this durability and the capacity for periodic regeneration continuously fail to resolve the deeper contradictions and provide the impetus for transforming such societies and their social relations at the same time.

In this article, we first examine the culture of "job consciousness" critically. Thereafter, we explore the implications of unemployment for conceptions of work and education. Following this, we deal briefly with alternative and socially useful forms of the organisation of work and with the meaning of these alternatives for educational processes and learning and conclude with a discussion of the implications of our arguments.

\section{CONSCIOUSNESS AND CULTURE}

The historically evolved processes of wage labour (characterised by the "wage relation" and its contractual forms) - consonant with the political economy of global corporate capitalism, is the basis of the contemporary social consciousness and culture about work, labour and jobs. It regards this relation as the norm that frames what is socially acceptable in modern capitalism. Although wage labour may have some association with the concept of "socially necessary labour," it signals more than a legal relationship. In political economy, wage labour signals several important elements of capitalist work beyond the technical capabilities implied and raises questions about its social and collective nature, forms of regulation, relations of power and exploitation, together with alienation in the process of production. This process simultaneously requires capitalist forms of control over the labour process, reconstructs the relationship between those engaged in the labour process and regulates the "price" of labour.

Its effects are exploitative, oppressive and alienating both economically and psychosocially for the majority of those engaged in the labour process globally-even while producing "challenging" work for a small minority of highly skilled (and rewarded) workers.

Global corporate accumulation is predicated on and reshapes social life in a variety of ways that stimulate its obsessive consumerism and the commodification of everything. This process of accumulation, as we can now see, results in and is simultaneously a consequence of the massive movement of populations from rural to urban settlements, new technological regimes extending the hegemony of corporate capital, inducing climate change and ecological destruction and mostly penury and neglect for close to a billion human beings globally. All of this is no less a consequence of the mystification of power in society through the subliminal and direct messages emanating from corporate control which informs the public consciousness or the "common sense," particularly in an age of rapid global communications. 
Often a narrow view - formally paid wage labour — constitutes the sum total of what is considered "work." The resultant social consciousness about the necessity and forms of labour/work and its uses are embedded and fostered in social culture by legal fiat and state policy - a view that is supported by the structures, regimes and systems of public and private institutions, the media generated public discourse, and in academic and non-academic learning contexts. In academia it is supported by the focus and content of research and intellectual production which has lent substance and content to a normative conception about work as a wage relation, despite contemporary feminist (and other) analysis highlighting for instance unpaid labour performed by women (Fraser 2016).

The troublesome reality is that the bulk of studies about post-school education rely almost wholly on neo-classical and now neo-liberal approaches to social issues. ${ }^{1}$ In South Africa these have little or no orientation to historical questions, nor appreciation of the relationship to communities that are marginalised and the socio-linguistic challenges inherent in all learning. Such approached make little reference to global ideologies and their impact in shaping educational regimes, and often simply reproduce much of the language of supply-side perspectives about the "needs of the economy." Studies that are explicitly critical of such approaches are largely on the margins - certainly not on the menu for undergraduate study, and so the linear relationship between education and the economy predominates.

A useful body of "progressive" critiques has developed reflecting on the complex nature of the relationship between work and society (Bowles and Gintis 1976; Carnoy 1984). This relationship is explored through social anthropology and history, and its relationship to social systems and individual and familial capabilities, the natural environment and most pressingly its political economy. This critique has considerable value because it is also attentive to the demands of deeper historical, gendered and racially relational accounts and locally based ethnographies even if these are not easily given to reductive generalisation or to grand theory. Such critical approaches lay the foundation for understanding more deeply not only the historical sociology of work but also its relationship to education, its curriculum, structures, and grounds of knowledge, constituencies, purposes, objectives and value.

Yet, there is rarely a simultaneous radical view of work situated in a radical view of education in relation to it. This means that even radical approaches to learning forego any orientation to a radical reconstruction of the social relations of work and how this might be of value to social justice and planetary sustainability.

1 A presentation at the Department of Higher Education and Training Seminar on 4 November 2014 titled "Responding to Shifting Demand for Skills: LMIP Report 4," is a graphic illustration of the reductive approach we refer to which relies on the troubling assumption that the only possible work is wage labour-leaving those outside of it as "non-citizens." 


\section{THE IMPLICATIONS OF (UN)EMPLOYMENT AND INEQUALITY FOR CONCEPTIONS OF WORK AND EDUCATION}

Motala and Treat (2014), in an article on the question of unemployment, lamented the way in which the phenomenon of unemployment is represented in the dominant public media. The authors argued that these representations marred any possibilities for a serious understanding of unemployment because they tendentiously reproduced the ideological perspectives of particular political and economic interests - to wit, powerful corporate interests, which demanded a specific orientation to both unemployment and its relationship to education and training. They examined the obfuscatory assumptions that informed such a perspective and prevented any intelligent discussion about the social reality of unemployment, its causes and effects and especially about how it was understood in the public domain. Following this, they argued that the "pervasive distortion of the causes of unemployment in mainstream reporting undermines possibilities for appropriate, effective policy and social action" $(2014,2)$.

The article by Motala and Treat (2014) does not deal with the question of how deeply implicated social and economic inequality is in the phenomenon of unemployment. We know this because even neo-classical approaches to economic systems recognise the effects of inequality on the potential for investment-led economic growth, which is critical for employment - even though such approaches avoid more fundamental questions about the ownership and control of investible capital, the role of speculation and financialisation and their impact on decisions relative to labour participation rates.

A recent review (Foster and Yates 2104) of the seminal publication Capital in the Twenty-First Century (2014) by the French economist Thomas Piketty, has shed critical light on the specific question of inequality and by extension is also useful in providing some insights into the relationship between inequality and employment. The review is pertinent for our understanding of the role of post-school education in society. The reviewers describe Thomas Piketty as a "highly credentialed member of the neoclassical economics elite," pre-empting any suggestion that his views are that of a "radical," "left oriented" or Marxist persuasion, and show how despite his intellectual orientation-as a neo-classicist - he has produced what must be one of the most insightful analyses of 20 th century capitalism.

The reviewers argue that the core capitalist economies are experiencing secular stagnation, characterised by negligible or no economic growth, rising unemployment and underemployment, and idle productive capacity. This refers in particular to the tendency of capitalist economies to stagnate over time, accentuated, they argue, by the phenomenon of growing inequality which is the subject of Piketty's book. They also argue that academic economists (referring to the self-same neo-classicists) have been implicated in the failure to understand this development in capitalism because of their attachment to the analytical framework of neo-classical economics ${ }^{2}-\mathrm{a}$ framework that 
has relied principally on two foundational premises. The first of these refers to their insistence about the tendency of capitalist economies to gravitate towards equilibriumsurmounting the problem of unemployment as a result of the interaction of supply and demand over time and obviating the need for any kind of intervention. That is, as Foster and Yates $(2014,1)$ explain, that

a freely competitive capitalist economy left to itself generates full employment, indicating that unemployment is the product of various frictions, imperfections, or government interference.

Second, (and critically for us) according to them the problem of inequality is no more than the consequence of unequal levels of productivity which reflect the differing relative contributions of the factors of production - land, labour, capital, and especially their applicability to the contributions of individuals to productivity. Thus, Foster and Yates $(2014,1)$ posit

a person's income is simply a function of his or her productivity and willingness to work. People are poor because they are not very productive or because they have a weak attachment to the labor force as a result of their own choices. Productivity is driven in the main by the willingness of individuals to invest in their "human capital," and the most important type of such investment is education.

This approach is based in turn on the risible idea that workers prefer not to work because of their preference for leisure time in place of work, while people who are rich are so because they work very hard for their higher incomes and are prepared to forego leisure for work. One has to extend the boundaries of belief to understand that this line of argument has a rich academic pedigree - with some of the most notable economists of the 20th century as its purveyors. As a result, Foster and Yates $(2014,8)$ assert,

The theory that came to dominate, beginning in the second half of the nineteenth century —and still does - was called "marginal productivity theory"; those with higher productivities earned higher incomes that reflected their greater contributions to society. Competitive markets, working through the laws of supply and demand, determine the value of each individual's contributions.

Added to this line of (un)reasoning is the idea that since technological development has been a spur to "human capital" development, those who do not aspire to enhance their "capital" are simply left behind in the competition for higher incomes. This argument is made even while acknowledging the role of public policy in ameliorating the effects of inequality, always subject of course to the caveats concerning the ostensible negative effects of free education on the incentive for doing hard work to develop the economy.

draw on to deal with this issue. Yet it remains the dominant body of economic thinking that is taught throughout most of the academic world - indicting academics not only for their lack of intellectual rigour but also for their ideological attachments to a much discredited body of ideas. A recent review of what is taught globally will show the extent of this uncritical attachment. A brief illustrative critique is to be found in Hossein-Zadeh (2014). 
The relevance of this for our discussion is about how we understand the likely trajectory of global development and whether we should interpret the demands for education and training as a stimulant to economic growth in a linear and uncritical way. In such a linear view the relationship between economies and educational systems is struck by the conundrum expressed by Says Law-the neo-classical assumption that supply creates its own demand, suggesting the "notion that full-employment equilibrium was an inherent tendency of the system" (Foster and Yates 2014, 2) of capitalism. John Maynard Keynes had subjected this line of thinking to thorough criticism invoking the hand of the capitalist state to stimulate the growth of the economy and employment. Galbraith $(1977,216)$ summed up Keynes's view as follows:

Keynes's basic conclusion can ... be put very directly. Previously it had been held that the economic system, any capitalist system, found its equilibrium at full employment. Left to itself, it was thus that it came to rest. Idle men and idle plant were an aberration, a wholly temporary failing. Keynes showed that the modern economy could as well find its equilibrium with continuing, serious underemployment. Its perfectly normal tendency was to what economists have since come to call underemployment equilibrium.

To understand the full significance of this, it is useful to quote from none other than the Nobel Laureate and former World Bank executive Joseph Stiglitz. According to Stiglitz, the rise of capitalism necessitated the "imperative to find new justifications for inequality, especially as critics of the system, like Marx, talked about exploitation" (Stiglitz 2012, 30).

A formidable array of economists continue to point to the capacity of capitalist economies towards stagnation, including, but not only, several Marxist economists who have also indicted the body of conventional economic doctrine for its inability to provide meaningful explanation of the crisis. Harvey (2014, xiii) talks about the need for a different "investigative method and mental conception" against the "barren intellectual times" of the present:

After all, the economic engine of capitalism is plainly in much difficulty. It lurches between just spluttering along and threatening to grind to a halt or exploding episodically hither and thither without warning.

It is clear for many that unemployment as a global and national phenomenon is here to stay for as long as the present organisation of society-in all its varieties of "freemarket" capitalism - is not transformed. The rise of a precariat as an inherent attribute of global corporate regimes (Standing 2011), the casualisation of labour and the persistent threat of joblessness for those who are employed are the inevitable consequences of the present systems of production, exchange, distribution and realisation compounded by the weaknesses of the social policies in dealing with these. The "social contract" which defined the tri-partism of advanced capitalist regimes in the Western world is in decline and social democratic policies have given way to the financialisation of the global economy. The present regimes of control over employment levels represent the 
response of global corporate capital to the contradictions of capitalist development and are irreconcilable with the requirements of a globally humane and just social system and planetary sustainability.

The technical requirements of industrial life were in turn stimulated by and gave rise to the reorganisation of social and human relations - now firmly predicated on the foundations of market relations, buttressed in time by an elaborate system of legal covenants presuming to bring the relationship between workers and capitalists under the "rule of law." As we now know, market relations are ubiquitous, but they would not have been possible without the expropriation of the independent means to produce wealth and livelihoods that attached to communities prior to the advent of capitalism. Production for exchange became the norm and labour power was one (even if the most critical) of the commodities available for the purpose.

These developing relations led ominously to the beginnings of "wageless life" (Denning 2010) as work, under the market relations engendered by the rise of capitalism, was simultaneously the progenitor of the phenomenon of unemployment.

According to Michael Denning, in its "classic" Marxist descriptions, "wageless life" is referred to as "the reserve army of labour" or sometimes as "the proletariat." For Denning $(2010,79)$ the idea that human beings are disposable is untenable especially since they are regarded as such by the effects of markets and states. For him the "accumulation of labour" and the process of its reproduction is itself the key to an understanding of the process of capitalist accumulation and consequently an examination of "wageless life" should take precedence over the condition of wage labour. Moreover, this implies, most importantly, not a deficit based definition but more fundamentally a condition of "wageless life" itself and rethinking the concepts of "unemployed and informal" (Denning 2010, 80). "Wageless" is therefore a parallel but more useful term from his perspective because he (Denning 2010, 80) argues

[t]he fetishism of the wage may well be the source of capitalist ideologies of freedom and equality, but the employment contract is not the founding moment. For capitalism begins not with the offer of work, but with the imperative to earn a living. Dispossession and expropriation, followed by the enforcement of money taxes and rent: such is the idyll of "free labour." In those rare moments of modern emancipation, the freed people - from slavery, serfdom and other forms of coerced labour-have never chosen to be wage labourers. There may be a "propensity to truck, barter and exchange one thing for another," as Adam Smith put it, but there is clearly no propensity to get a job.

Understanding the relationship between the global and local economy and its demands on education remains critical because of the powerful and pre-emptive grip these make on the very possibility of employment shaped by conceptions of "relevant work" and an obeisance to the requirements of such work through education and training systems. Wage labour, we now know, is increasingly becoming more and more characterised by the life of "wagelessness." It has the power of reconstructing the very conception of citizenship - since without work the benefits of citizenship seem to be out of reach for 
so many, through the globally exclusionary forms of gendered, racist and ecological ideas and practices that sustain them (Barchesi 2011).

Denning's (2010) provocative approach is apt for much of the process by which "wageless life" has emerged from the rich heritages of prior experience in ruralbased production in South Africa out of which the process of conquest created a class of migrant labour. These workers and their families were held hostage to the wage economy and dispossessed of the means of livelihood in the emerging edifice of the formal economy. In this sense unemployment was no less the effect of creating wage labour as the dominant norm of social life. It provided the historical and conceptual form by which employment appeared as the societal standard, obfuscating the reality of its origins in the process of dispossession.

\section{ALTERNATIVE AND SOCIALLY USEFUL FORMS OF THE ORGANISATION OF WORK-A BRIEF ACCOUNT}

If the phenomenon of unemployment is irreversible in and through extant social organisation, we are obliged to examine forms of work that fall outside these conventional economic and normative categories. There is and has to be life outside these normative forms given the wide diversity of work that takes place in the interstices of capitalist production even though it is often wracked by contradictory forms. Work is integral to our collective being and needs to be wrested from the terrorising grip of its present organisation, since (Eastern Sociological Society 2013)

[p]aid jobs are only part of the picture. People also work to find and keep jobs and homes; to nurture others; to build communities; to access services; and more. Migrants and refugees work to sustain transnational families and build new lives. People work to establish and transform identities, protect privileges, and resist the indignities of marginalization. They work to make change. Children work, in the informal economy, as well as at home, in school, and in their communities. Many people have long worked in shadow economies; some have begun to create new kinds of local economies. And new technologies are producing novel forms of work that are only beginning to be understood.

Despite the alienating characteristics of capitalist labour that place almost insurmountable limits on personal development and the realisation of one's potential, there remain "glimmers of possibility in the conditions that capital's use of labour dictates" (Eastern Sociological Society 2013). Not all is "doom and gloom" despite the socio-psychological problems generated by an era of neoliberal ideas where even the mild concessions of capitalist forms of knowledge have been reneged on in the name of austerity, as Harvey (2014) argues.

We know that some forms of work are direct extensions to capitalist production reproducing it in various ways. Many are simply responses in desperation without any conception of an alternative, i.e. forms of work based on the necessary labour to survive the framework of existing relations. Some are contradictory because they are not 
amenable to commodification in the context of market relations. As forms of segmented labour they give rise to a multiplicity of real and imagined divisions and interests which are fluid, interchangeable and yet partially useful to capital. These too have implications for agency - for the forms of combination and organisation or the lack of it, and the ability of workers and the other marginalised communities to deal with the power of capitalist relations.

The question we have to ask is about how we conceptualise the difference between the forms of work that, on the one hand, are largely responses to the crisis of personal and community lives - subsistence and sub-subsistence and other forms of work-from the potentially more direct challenges responding to the alienating characteristics of capitalist production.

A whole range of socially organised forms of work both as alternatives to formal wage labour and in response to its marginalising effects have developed in a variety of contexts to provide meaningful avenues for livelihoods and social life. The concept of livelihood refers to attributes of work and work relationships that transcend the idea of a means to make a living and implies "ways of living" which recognise socio-economic life and political, historical, geographic and other contextual factors affecting the options available for producing a living. In such an approach it would bear reference to social institutions such as the family and community, gender relations and geographic attributes, cash and in-kind incomes to take into account the "wider spatial context" that is implicated in such an approach to conceptualising livelihood (Staples 2007). These refer to avenues of work sometimes described as "livelihoods at the margins" and could include activities which range from individual to collective responses to the failure of the market in producing useful forms of employment. Some of these initiatives include the formation of common wealth trusts, production, consumption and distribution cooperatives, solidaristic economies, climate change jobs not subject to "greenwashing," occupied factories, communes and stokvels ${ }^{3}$ amongst other forms of socio-economic and livelihood organisation. Each of these forms has specific characteristics although they together represent alternatives to the dominant capitalist modes of economic organisation based on alienating and exploitative social relationships and unequal power.

While each of these can be described in some detail, that is not possible or necessary here. They represent important differentiating characteristics relative to conventional forms of commodified work. They represent moreover the emergence of literally hundreds (if not thousands) of small "independent" and self-sustaining initiatives which relate to households, and communities developing autonomous (and sometimes solidaristic) economies. Many of these are likely to be driven by women in communities characterised by absent men seeking employment in the formal economy.

3 A savings society where community members regularly contribute an agreed amount and from which they receive a lump sum payment at regular parties (or stokvels). A widespread phenomenon in South Africa's working class townships. 
Each of these remains fragile and many are embryonic, and can fail. Their sustainability is the critical issue and it raises important historical and conjunctural questions for all of those immersed in the social "mobilisation" of alternatives. In South Africa at this time, a few of these initiatives have taken on the role of engaging the state in a strong sense.

Democratic states and their resources are without doubt critical of any social reorganisation and democracy in the state is stimulated or retarded by synchronous social processes. Waiting for the state to democratise itself has no historical precedent. There is no alternative but to struggle for such democratisation by creating the spaces for engaged and active citizens to play the crucial role in this regard. Alternative approaches to the "fundamental structures of power" need to be explored more fully because of the growing recognition of the power of such alternatives not beholden to conventional forms of organising based on production processes in the main. Yet questions about how these forms of organisation are oriented to the state remain to be resolved since these non-conventional forms of organising are not, as Harvey explains (2015),

[b]ig enough on [their] own to actually deal with the fundamental structures of power that need to be challenged. Here we talk about nothing less than a state. So the left will have to rethink its theoretical and tactical apparatus.

It is also clear that these emergent organisations are yet to develop their orientation to the practical issues of relating education to work more fully-even though they are engaged in the daily socialisation of work in practice and the application and enhancement of knowledge for development. In this sense, theorising the role of education is as yet somewhat rudimentary though strongly reliant on past conceptions of Freirian approaches to adult learning, curriculum and pedagogy.

In a sense the rapidity or slowness of these processes represent a failure not of the communities - but of "educated elites" whose role can be to initiate, facilitate and foster the process of wider understanding and consciousness together with communities, as engaged intellectuals and socially responsible citizens who have the advantage of years of "scholarly" learning and reflection. Some of the weakness of locally based organisations can be attributed in part to the indifference of elites to their democratic responsibilities and the "boycott" of the processes of autonomous local democratic development. This is perhaps the biggest failure of the role of universities and the institutions of learning more generally and less of the public bureaucracy, whose conceptions are limited by the immediacy of the need to reproduce social roles uncritically. In this regard, there is in academia, for instance, a staid view about the concept of "voice," which is critical of it. Its critique relates to epistemological questions - i.e. questions about whether the knowledge obtained through the process of engagement is "authentic." In fact, the accusation levelled at engaged intellectual work is that it is driven much more by "romantic" ideas than by "rational" or intellectually defensible modes of "knowledge production." In this way, (and whatever the merits of that argument) the problematic role of intellectuals and academics in society is reduced to a debate about how knowledge is organised and developed - abandoning any reference to the underlying purposes in 
society. Questions about the integrity of sources and the accuracy of interpretations, and especially about the role of intellectuals in this, are extremely important although such questions should be subsumed under the larger question of the obligations of intellectuals as engaged citizens - engaged in the difficult and sometimes "messy" realm of public reasoning, activism and being.

The alternatives referred to above represent much more than the technique of survival used by marginalised communities. They present to us possibilities based on the production of socially necessary and useful goods and services - outside the forms of commodification that are at the heart of capitalist production. Such an arrangement also deepens democratic social control and accountability based on a mixture of community and personal systems of ownership having relative independence from conventional market mechanisms and generative of a broader solidaristic economy. These exemplify ways of avoiding traditional capitalist pricing mechanisms in favour of new ideas about pricing, exchange, distribution and social reserve in the absence of the possibility for large-scale national planning. They also open up possibilities for the development of a system of agro-ecology as a viable solution to the need for food sovereignty freed from the structural inequalities and the prevailing arrangements of power as well as community-based work in health, education, child and frail care, and cooperative forms of production for school and public sector institutions offering nutrition based on localised work. Other examples include municipal works projects requiring infrastructure construction, water reticulation, housing and related services and a wide range of "development" initiatives to meet local needs - properly understood as public work. As Weinberg (2015) avers

Public work is the ability to move beyond seeing civic opportunity to actually working with others to create things of lasting social value, the essence of a free and democratic society. I would argue that public work is the defining outcome we are aiming for when we talk about civic education and community-engagement efforts.

\section{AND WHAT OF LEARNING, KNOWLEDGE AND EDUCATION?}

How these alternatives affect any orientation to the role, forms and purposes of education is a question which needs detailed exploration which is not possible here. However, it is possible to signal some of the implications for education and training systems. It should be clear that in the first place what these alternatives imply is a much broader view of the role of education than is contemplated by the dominant discourse which regards education as an instrument of the labour market or even as the foundation of a "liberal" and democratic society. The important issue for us is that in addition to the broad and multifaceted purposes of education in enhancing ideas of social justice and citizenship, education should also orient itself to supporting the development of useful livelihoods 
and the production of socially necessary goods and services for the survival and growth of societies.

In this regard, Southern Africa has been the locus of a very important initiative that was overtaken by the rapid development of racial capitalism, shutting out its potential as an alternative possibility for education. This alternative is worth re-examining as an approach to education and training under a set of relations not so intent on destroying social lives and marginalising rural and urban poor communities. We refer here to Patrick van Rensburg's (1974) Report from Swaneng Hill, which was an extremely useful experiment, and practical example which could have far reaching consequences for the shape of the education and training system and has continued relevance even if conditions have changed quite considerably from the time of its writing.

The report describes in some detail the beginnings of the project, the many ideas that were developed towards the goal of relating education to productive work, the relationship between education and social justice through access at a time when African governments were introducing policies for "development," and for education as a "major tool of this modernisation" (Van Rensburg 1974, 19). It confirms the importance of recognising the capabilities of students and teachers in the educational process as opposed to regarding their ideas and practices as marginal to the larger policy objective of modernisation. Innovations included the creation of "brigades" which formed the first significant structure for "self-help" and the inculcation of ideas of social justice through the curriculum. The experiment made education "less costly, less exclusive and available to greater numbers of people," linking what was learnt with skills that were directly useful to projects that were socially relevant in the context of limited resources and which were reinforced by "timetable discussions with the students about their society and the country's economy" (Van Rensburg 1974, 21).

The report describes a "development studies" course provided to students in some detail, which included sections of economic analysis (referring to such topics as production, consumption, investment, surpluses, money, employment population growth, accumulation, resource allocation and the like). The course also studied preindustrial societies and the agricultural revolution, the use of natural resources and the growth of innovation and scientific progress as well as the history of innovation preceding its appearance in Europe. The course analysed how the ruling classes controlled surplus production. Study material described the exploitation of women and children's labour in the processes of industrialisation, slavery and colonialism and the consequences of the process of industrialisation along with the pros and cons of intermediate technology and labour intensive methods. Finally, the course discussed the relationship between social and cultural change and economic development and the role of students in human development and rural development (in the context of Botswana) in particular. Van Rensburg's approach to the curriculum was Freirean in that it was shaped by his view

4 Explained in detail under the discussion of Boiteko (self-help and self-reliance) (Van Rensburg 1974, 42). 
of the attributes brought to education by its learners and how these affected their ability to learn.

After returning from exile to South Africa, Van Rensburg developed and presented a course on "Education with Production" (EwP) from 1992 to 1994 as part of a Bachelor of Education programme at the universities of Cape Town, Natal and the Western Cape and conducted a series of seminars on EwP with provincial education departments between 1995-1999. He also initiated projects in Mpumalanga including the Betrams Development Brigade aimed at educating and training unemployed youth in constructing housing units and renovating derelict buildings (Van Rensburg 2001). It is useful to quote Van Rensburg $(2001,129-30)$ at length about what he refers to as "unfinished business":

A number of meetings have been held by FEP [Foundation for Education with Production] with MECs [Members of Executive Councils - the cabinet of provincial governments] in Provinces to discuss projects related either to the EwP curriculum or Brigades, without progress ... The Heads of Curriculum of nine Provinces agreed at a meeting in September 1988, attended by me as Director of FEP, to a follow-up one-day workshop to discuss the EwP curriculum. Not only was the workshop never held, but FEP never received any reply by telephone or letter to its reminders that such a meeting had been scheduled and our enquiries as to when it might be held. ${ }^{5}$ Perhaps the most serious omission, however, relates to the failure to pursue the recommendation of the 1998 Jobs Summit about the Brigades. Here, I can only repeat what I was told by a highly placed official in the National Department of Education who would be critical to pursuing the recommendation, (and who worked in trade union education in the struggle), namely that "Brigades have not succeeded anywhere."

A clearly frustrated Van Rensburg (2001, 130-31) laments:

Whereas in the past, liberation movements in Southern Africa had radical visions of broad socioeconomic and political policy, and of education systems that would promote and serve them, today the various governments they gave rise to have almost all settled for the prevailing neoliberal realities of a global free market ... Most South Africans have tunnel vision about formal education and the capacity of matriculation to secure jobs. Many of its jobless fall prey to a burgeoning education industry, and to the diploma disease ... In the course of its struggles, the ANC had looked with interest at alternatives in education and health and medical provisions. It would have looked at the potential of alternative technologies, alternatives in agriculture and alternative energy, especially in rural development, but also in housing and job-creation initiatives in towns and cities ... South Africa seems now to hold alternatives in contempt, seeing them as beneath its dignity as an advanced industrialised country.

5 Van Rensburg (2001, 130-31) added "Similarly, the Betrams Development Brigades has received no support, financial or technical, from either the Department of Education or of Labour, at either National or Provincial level. Visits were made by three persons from the Department of Education to the project, about which they were positive, but there was no follow-up action to any of the visits. An invitation to the Deputy Director General was refused." 
We are enjoined by these compelling views to be more fully conscious about the challenges to the dominant forms of production, consumption and distribution and their consequences for educational interventions which seek to introduce new approaches to learning, social consciousness and its systemic development. Not recognising some of the intractable challenges of such interventions would be naive and could have adverse consequences for any attempt at supplanting the power of what we have at presentthe ideas of human capital development underpinned by global neo-liberal dogma. Supplanting the extraordinarily resistant contradictions between capital and alienated labour is not adequate unless the "other contradictions" relating to the "money form" and the "private capacity to appropriate social wealth" are also dealt with (Harvey 2015), and unless one accepts a long-term orientation to building an alternative"brick-by-unyielding brick." This means that it should be clear that attempts to create such alternatives such as through cooperatives, worker control and even the more recent expressions of solidaristic economies are likely to meet with limited success.

The barriers that face any attempt to construct an alternative system should not be underestimated since innovations that are intended to counteract the power of conventional systems invariably face strong resistance. Moreover, questions about the scope of alternative interventions arise almost inevitably from the perspective of planners and bureaucrats dealing with large national systems. This question has also entered the vocabulary of some academics who seek to provide "solutions" in place or to provide analytically rigorous critique which might be of use to policy-makers and the answers they seek. Systemic transformation is not simply about large-scale planning or the wider and immediate replicability of particular interventions. It is much more about changes in the public consciousness, the ability to demonstrate the efficacy and social relevance of new approaches, their sustainability, the strategies that would be required to deal with resistance to change and the organisation of the public agency to engender and support the processes for change. This is dependent on the role of intellectuals for the critical evaluation of the strengths and weaknesses of what is proposed as an alternative, foregoing the attractions of linear "solutions" and discussions about the resources and other requirements or the appropriate "policy interventions." In effect, a long-term orientation is required for any fundamental reorganisation to succeed.

In this regard, some issues augmenting the important propositions raised by Van Rensburg need much more consideration than is possible here. Amongst these is the revitalisation of civic education and civic learning as important to new conceptions of work and citizenship. It would imply the development of ideas about work as intrinsic to any conception of citizenship, for example developing the capabilities of "citizen teachers" or "citizen faculty members," and other similar socially conscious applications of work drawing on past experience. Such an initiative was exemplified for example in the work of the black consciousness movement and its activists on what was called "black community projects" in the seventies and on the important experiences of "education with production" in the Southern African region. 
The relationship between work and learning must be regarded as emancipatory for both work and learning and not largely - as we think it is presently conceived in many places - as "change oriented workplace learning." In the latter practice, the conception of learning is central to the relationship with work but does not problematise the nature of the workplace itself and the social relations or the relations of power it reproduces. We have to take further the argument made by Cooper and Walters $(2009, \mathrm{xx})$ that

power relations are key to understanding learning/work processes, and that the global political economy and policy contexts have shaped social relations and impacted on learning processes, knowledge hierarchies, and educational policies and practices.

The critique by Cooper and Walters can be addressed by examining both the forms of learning and those of work that are key to the "global political economy," simultaneously. This means that, for example, workers' education cannot be simply about the present forms of work and the validation of prior learning or lifelong learning but has to be about new socially determined forms of work related to new conceptions of production and realisation outside the framework of exploitative and oppressive systems. There is a great deal of experience based on the work of many Freirians here and their work over the years, including the history of such pedagogical development through organisations like the South African Committee for Higher Education (Coleman 1990; Motala 2017) and others in the past. We simply have to recall these ideas and the strategies developed with them. These included a "pedagogy of contingency" which responds to context and new discovery, taking into account conditionality, chaos and uncertainty in dealing with the dynamics of changing social relations. This will inevitably imply a careful look at the best methodologies of enquiry for promoting what might be called "public and participatory" methodologies so that the issues, context and modes of participation in the research process are planned fully beyond their present limits. We know that there are real possibilities in this direction in the organisations that have grown autonomously as a consequence of the present social and political crisis. In addition, as we are finding out, there are many such organisations in our communities.

An orientation to the concepts of work and education which avoids the danger of becoming categories of accommodation to the multiple forms of their commodification is therefore of great contemporary value. Implicit in our definitions and analysis of these concepts is the prior question of "what social system." For example, we do not seek more and wider recognition of women's work and a validation of women's contribution to society, without asking the question about what kind of society are we talking about. Nor are the challenges to workplace learning simply about "empowering" workers within the framework of existing "labour relations." Put another way, we are interested to know how the specific form of work ("women's work" or other) leads to social ends that do not reproduce the forms of prevalent social power. It means making capitalist relationships more explicit in our approaches to concepts like lifelong learning without treating its production systems as inevitable and normative, and re-examining 
concepts about lifelong learning relative to work and its contradictory applications. This requires an elucidation of the theoretical reappraisal of the work/learning relationship as presently conceptualised against the "materiality" of capitalist social relations, which are gendered and racialised, in order to elicit new forms of social organisation - and therefore of work in a new relationship to the acquisition of knowledge, practical know how and wisdom.

\section{THE IMPLICATIONS OF OUR CRITIQUE}

Policy makers, academic analysts, social commentators and all those concerned with "transformation" need to explore more fully the relationship between the alternative livelihood, socio-economic, citizenship-based and cultural and solidaristic activities in which especially the most marginalised sections of society are engaged together with the learning that takes place in the alternative activities of such communities. Such an exploration would provide a stronger theoretical, practical and organisational basis for an alternative, more robust and meaningful curriculum - not determined by the requirements of capitalist labour markets but by the requirements of a democratising society, seeking support for the self-generative activities of such communities towards the development of a conscious and engaged citizenry.

Furthermore, this has implications for the process of knowledge development. New areas and programmes of research can be developed arising from the growth of alternative educational systems, processes and actions, appropriate criteria for educational assessment and practical arrangements for a wider range of educational settings, including volunteer-based advanced learning. Careful attention needs to be given to participatory processes in which communities are directly involved in research, curriculum and pedagogical planning.

Our approach suggests that educational phenomena must be examined from the perspective of a range of academic disciplines. For instance, while looking at inclassroom practice it is obvious that factors relating to how teachers teach and learners learn, the curriculum, text, language and their related issues have a large role to play. However, this role too is circumscribed by the conditions which provide the sociolinguistic context that impacts on how learning takes place. So too for instance, we know that nutrition is critically important in making learning possible and that its absence inhibits the process of acquiring knowledge since social issues like the background of learners is implicated in the health and education of a learner. Yet there is a wider set of considerations to be taken into account even here since, as we have observed, the issue of language (and culture, tradition and practice in the home) is as central to the construction of the process of learning and the pedagogical strategies implied in this.

We are also obliged therefore to avoid linearity and simple causalities and to pay regard to the relationship between the complex interplay of the sociological, political (policy and political choice related), economic, linguistic, cultural, and ecological issues which need to be brought into a framing analysis to understand complex social 
phenomena more fully. Greater support for research that transcends disciplinary limitations is necessary to examine such alternative approaches and much more needs to be done beyond an examination of the efficacy of the post-school legislation and its implementation or the institutional structures, governance and management of TVET, and the curriculum and qualifications appropriate to post-schooling. While the latter have importance for informing policy and institutional practice, such research should not be hamstrung by the limitations of formal education systems and formal labour markets to the exclusion of all else. Progressive research should strive to situate its enquiry within a framework of alternative approaches to power and agency, both as means and ends to a society freed from the limitations of wage relations, market-based ideologies and the cultural consciousness these produce. Such research could deepen our understanding of work as it has evolved historically towards its present form in the ubiquitous formal labour markets characterised by "brokered," "underutilised," "wasted," "underemployed," alienating and marginalised forms of work in their gendered and racist incarnations in both the North and South, "centre" and "periphery," in global regimes of production.

We need to examine even more deeply the uses of concepts familiar to the world of progressive education, like adult learning, lifelong learning, continuous learning, access, non-formal learning, inclusion and exclusion and participatory learning in relation to alternative social forms of work organisation. Moreover, inherent to such an approach is a better understanding of socio-linguistic requirements of educational systems drawing on ethnographic accounts of the life of the most socially marginalised. The latter accounts are useful to understand better the lives, experiences, knowledge, aspirations, political and social traditions and the struggles of the communities of the rural and working classes. These ethnographies provide a depth of qualitative understanding not given to more quantitative methods. The advantage we see in ethnographic work is derived from the possibility of acquiring historical and contextual "evidence" beyond the data available through more conventional forms of enquiry.

Moreover, the alternatives we suggest relative to work and learning should be consistent with progressive ways of thinking about sustainable planetary ecology. As Foster asserts $(1994,142)$,

The relentless privatization of nature and production ... leaves little option - if human beings are to continue to advance - other than the socialization of nature and production. Only in this way can the conditions of life and human existence be safeguarded. Since work constitutes the basis of the human relation to nature, the socialization of nature can only be fully realized if accompanied by the socialization of production.

This relationship between production and nature too requires a deeper understanding of the possibilities for new forms of work based on cooperative, collective, democratic and other genuinely alternative forms of socially useful learning.

Ultimately, our research and the work we do should enable us to explore the fuller possibilities that exist for the production of strong and purposeful research and practical 
ideas based on integrative science and engaged scholarship, and social consciousness based on a broader intellectual perspective for committed educational activism inspiring public and democratic agency. We suggest that it is necessary to examine the form, content, methodologies, and praxis related to the idea of socially useful work as intrinsic to the relationship between education and training, work and society. This should be done neither solely as a response to corporate power, nor simply as a reform of the legacies of the apartheid state, but as transformative of social life, livelihoods, citizenship and rights. The latter areas should be predicated on a fundamentally different organisation of social power and on the agency of those in society most affected by the present arrangement of social relations in the labour market and its associated forms of education and training. Most of all, it requires us to demonstrate the possibilities, efficacy and socially just implications of such transformative approaches bearing reference to local and other experiences in the quest for work and learning as useful for the realisation of humanistic values. We can only hope that this provokes us all to think about the intellectual challenges for producing a radical and alternate consciousness, culture and society.

\section{REFERENCES}

Barchesi F. 2011. Precarious Liberation: Workers, the State, and Contested Social Citizenship in Postapartheid South Africa. New York: SUNY Press.

Bowles, S., and H. Gintis. 1976. Schooling in Capitalist America. London: Routledge and Kegan Paul.

Brown, P., H. Lauder, and D. Ashton. 2011. The Global Auction: The Broken Promises of Education, Jobs, and Incomes. Oxford: Oxford University Press.

Carnoy, M., and H. Levin. 1984. The Dialectic of Education and Work. Stanford: Stanford University Press.

Coleman, G. 1990. "A History of The South African Committee for Higher Education (SACHED) 1959-1987." MA dissertation, University of Natal.

Cooper, L., and S. Walters, eds. 2009. Learning/Work: Turning Work and Lifelong Learning Inside Out. Cape Town: HSRC Press.

Denning, M. 2010. "Wageless Life.” New Left Review, no. 66, 79-97.

Eastern Sociological Society. 2013. "Call for Submissions: Invisible Work 2014 Conference.” Accessed November 14, 2017. http://www.essnet.org/annual-meeting/call-for-papers/

Foster, J. B. 1994. The Vulnerable Planet: A Short Economic History of the Environment. New York: Monthly Review Press. 
Foster, J. B., and M. D. Yates. 2014. "Piketty and the Crisis of Neoclassical Economics." Monthly Review: An Independent Socialist Magazine 66 (6). Acccessed November 14, 2017. https://monthlyreview.org/2014/11/01/piketty-and-the-crisis-of-neoclassical-economics/

Fraser, N. 2016. “Contradictions of Capital and Care.” New Left Review, no. 100, 99-117.

Galbraith, J. K. 1977. The Age of Uncertainty. Boston: Houghton Mifflin.

Harvey, D. 2014. Seventeen Contradictions and the End of Capitalism. Oxford: Oxford University Press.

Harvey, D. 2105. "Consolidating Power." Interview with A. K. Malabocas. Roar Magazine. Accessed November 14, 2017. https://roarmag.org/magazine/david-harvey-consolidating-power/

Hossein-Zadeh, I. 2014. "Class Interests as Economic Theory." Counterpunch, November 14. Accessed November 14, 2017. http://www.counterpunch.org/2014/11/14/class-interests-as-economic-theory/

Hyslop-Margison, E. J., and A. Sears. 2006. Neo-Liberalism, Globalization and Human Capital Learning: Reclaiming Education for Democratic Citizenship. Dordrecht: Springer.

Klees, S. 2017. "Beyond Neoliberalism: Reflections on Capitalism and Education." Policy Futures in Education. https://doi.org/10.1177/1478210317715814

Morris, W. 2008. Useful Work versus Useless Toil. London: Penguin Great Ideas.

Motala, E. forthcoming 2017. "Alternative Education: Examining Past Experiences Critically." In Reflections on Knowledge, Learning and Social Movements: History's Schools, edited by A. Choudry and S. Vally. London: Routledge.

Motala, E., and J. Treat. 2014. "Misrepresenting Unemployment: Evidence and Implications." Post-School Education Journal 1 (1): 16-8.

Piketty. T. 2014. Capital in the Twenty-First Century. Cambridge: The Belknap Press of Harvard University Press. https://doi.org/10.4159/9780674369542

Standing, G. 2011. The Precariat: The New Dangerous Class. London: Bloomsbury Publishing.

Staples, J., ed. 2007. Livelihoods at the Margins: Surviving the City. Walnut Creek: Left Coast Press.

Stiglitz, J. 2012. The Price of Inequality. New York: W.W. Norton \& Company.

Vally, S., and E. Motala. 2014. Education, Economy and Society. Pretoria: UNISA Press.

Van Rensburg, P. 1974. Report from Swaneng Hill: Education and Employment in an African Country. Stockholm: Almqvist and Wiksell and the Dag Hammarskjold Foundation.

Van Rensburg, P. 2001. Making Education Work: The What, Why and How of Education with Production. Johannesburg: Foundation for Education with Production International.

Weinberg, A. 2015. "Preparing Students for Work as Citizens." In Democracy's Education: Public Work, Citizenship, and the Future of Colleges and Universities, edited by H. C. Boyte. Nashville: Vanderbilt University Press. 